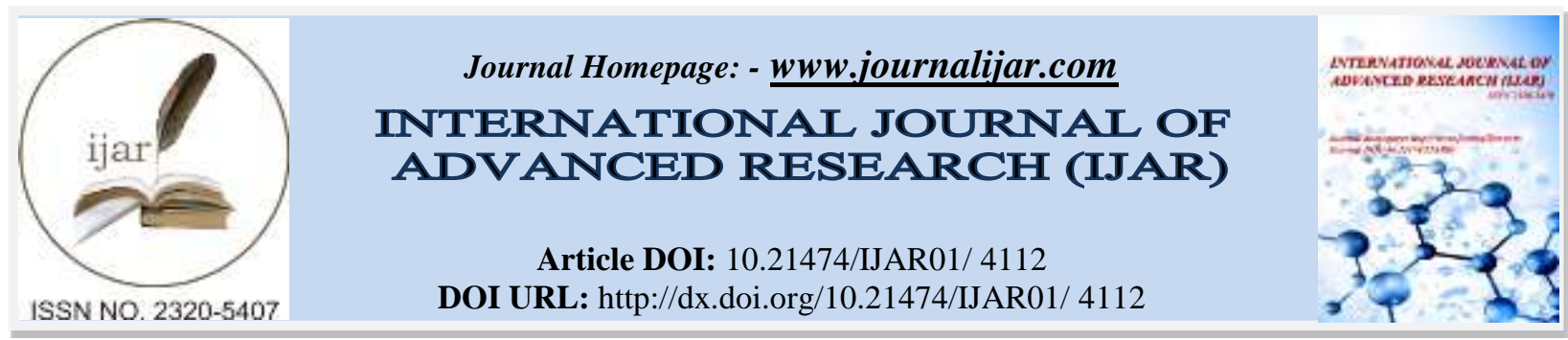

RESEARCH ARTICLE

\title{
ASSESSMENT OF FACTORS AFFECTING THE UTILIZATION OF PREVENTION OF MOTHER TO CHILD TRANSMISSION (PMTCT) OF HIV/AIDS.
}

Medical School, Tongji University. Shanghai, China.

\section{Manuscript Info}

Manuscript History

Received: 12 March 2017

Final Accepted: 14 April 2017

Published: May 2017

Key words:-

HIV/AIDS, Ethiopia, Mother-to-child

transmission,

\section{Abstract}

Despite the remarkable achievement in the coverage, there is a widely held concern that PMTCT activities have been lagging behind in Ethiopia. Although health institution and the health professionals working there are providing obstetric and neonatal care of a significant proportion of the population. There are adequate studies done to evaluate the situation related to PMTCT services in these facilities. This survey was intended to assess the possible factors affecting the prevention of Mother to Child Transmission of HIV/AIDS. During the study period across sectional survey was used as a method for this assessment. The finding of the study indicated that unprotected sexual intercourse (89\%), contaminated sharps (84\%) and mother to child (79\%) were the main mode of transmission of HIV/AISD identified by the woman knowledge gap and inadequate counselling were identified. Knowledge of the patient on the strategies of PMTCT and is importance on non - HIV positive birth and lack of integrating family planning to PMTCT are the main factor. Integrating HIV treatment and care services with HIV prevention interventions is vital to avert HIV positive birth. Improving patient awareness on PMTC has to get great attention and different strategies should be devised to cope-up the problem.

Copy Right, IJAR, 2016,. All rights reserved.

\section{Introduction:-}

Mother-to-child HIV transmission MTCT is the second largest mode of HIV transmission worldwide. Accounting for 370.000 infection in 2007 [1]. Most of these infections occur in the developing world particularly in subSaharan Africa, where the prevention of mother to child transmission PMTCT remain a promising, yet complex and challenging programmatic undertaking in 2007. Uptake for antiretroviral for PMTCT (ART-PMTCT) reached 33\% in sub-Saharan African [2]. In 2009, an estimated 1.4 million (0.9-1.8million) pregnant woman in low -and middle income countries were living with the human immunodeficiency virus (HIV) [3]. Pregnancy in an HIV -positive woman often carries serious consequences. Without treatment, HIV-infected mothers pass the virus to their newborns. Many of these children eventually sicken and die of AID [4].

Each year. Many children are newly infected with HIV .manly through mother -to-child transmission. An overwhelming majority - more than 90 per cent- of HIV infections in infants and children are passed on by mother during pregnancy, labor, delivery or breast feeding without any intervention, between 15 percent and 45 percent of infant born to mother living with HIV will become infected (5-10) per cent during pregnancy 10-20 percent during 
labour and delivery and 5-20 percent through breastfeeding. Approximately 50 per cent of infants infected with HIV from their mothers die before their second birth day [3, 4]. In 2009 an estimated $26 \%$ of the estimated 125 million pregnant woman in low and middle -income countries received an HIV test. However some women refuse to be tested because they fear learning that they a life -threatening condition; because they distrust HIV tests or because they do not expect their results to remain confidential, and fear stigma and discrimination following a positive result [5].

To achieve a high success rate, PMTCT programs must have well-trained, supportive staff who take great care to ensure confidentiality. They must be backed up by effective HIV testing and counseling programs and by good quality HIV /AIDS education, which is essential to eliminate myths and misunderstandings among pregnant women, and to counter stigma discrimination in the wider community[6]. In Ethiopia, progress has observed in the provision to reduce HIV transmission from infected mother to newborns by increasing the proportion of women who get tested and know their result through expanding rapid testing to many PMTCT sites. Percentage of HIV -positive pregnant women who receive antiretroviral medicines to reduce the risk of mother to child transmission was $8 \%$ in 2008/2009. A total of 1,023 health facilities were providing PMTCT Services at the end of 2009 [7].

The major gaps and challenges identified in limited studies in the implementation of PMTCT in Ethiopia include: limited expansion of The service ; inadequate use of PMTCT service even where it is available ; poor early infant diagnosis, poor integration of PMTCT with ANC services; low ANC coverage ,low percentage of deliveries attended by skilled health personnel; limited number of skilled and motivated of human resources, poor community component; of PMTCT; weak community - health facility referral linkage; poor male partner involvement ;and a weak Monitoring \& Evaluation system[7, 8]. Even though ,few studies have been done in the area, numerous things remain untouched to show the extent of the gaps and challenges in the prevention of Mother to child transmission PMTCT of HIV/AIDS services. Thus this assessment is intended to identify the factors that affect the services ,particularly from the clients aspect so as to put valuable to improve the level of services [8].

Pregnant women who are infected with HIV, the virus that causes AIDS, face an increased risk of poor pregnant outcome and the possibility of transmitting the virus to their newborn .in most HIV -infected, HIV does not cross the placenta from mother to fetus. As long as the mother stays relatively ,the placenta help protect the fetus from infection .if the mother has other infection that affect the placenta, if her HIV infection is new, or if she has advance HIV or malnutrition, the placenta may not be able to protect the fetus from infection [11].

Mother-to-child transmission (PMTCT) is when an HIV- infection women passes the virus to her baby. This can occur during pregnancy, labor and delivery, or breastfeeding, without treating. Around 15-20\% of babies born to HIV positive women will become infected with HIV during pregnancy and delivery; the other $40 \%$ occurs through breastfeeding .if breastfeeding continues from birth until 24 months -12

\section{Risk factor for Mother to child Transmission:-}

If a women is infected with HIV, her risk of transmitting the virus is reduced when she stays as health as possible .smoking, substance abuse, vitamin A deficiency, malnutrition and other infections. Such as sexually transmitted infection .are all associated with higher rates of mother - to - child transmission of HIV. Certain characteristics of the virus ,such as the viral load (quantity of the HIV virus that is in the blood) and the clinical stage of the HIV infection, also contribute to the chances of transmitting the virus to the newborn .in addition , factors related to labor and childbirth (preterm birth , placental disruption, duration of membrane rupture, whether the birth is a vaginal or cesarean birth) affect the risk that a women will transmit the virus to her child finally ,breast infection (mastitis),breast abscesses and nipple lesions increase the risk of HIV transmission through breastfeeding [13].

\section{Scope of the problem:-}

Sub-Saharan African-HIV prevalence rate among 15 to 24 years-olds have reached $36 \%$ in Botswana and $25 \%$ in Swaziland, Zimbabwe, and Lesotho, Sentinel surveillance among pregnant women, which reflects prevalence in the general population, has shown prevalence of greater than $40 \%$ in some parts of Botswana, Zimbabwe, and Swaziland .UNICEF estimates that close to 1.8 million pregnant women living with HIV/AIDS deliver 600,000 to 700,000 infants with HIV/AIDS annually. Ninety-five percent of children with HIV/AIDS are born in developing countries and an estimated 14 million children have been orphaned due to AIDS in 2002 [13, 14]. 
Ethiopia-A total of 1.023 health facilities were providing PMTCT services at the end of 2009 .More than 616,763 pregnant women made at least one antenatal clinic visits during the last fiscal year, and 417,841 underwent HIV testing, of which $10,267(2.4 \%)$ of the pregnant women tested positive .of the total pregnant women diagnosed with HIV, only 6,466(63\%) received antiretroviral prophylaxis (ARV/NVP) and only 5,025 infants received PMTCT prophylaxis in the same year. The proportion of diagnosed HIV positive pregnant mother receiving antiretroviral prophylaxis was significantly greater than 52\% in 2007/08(7, 14). From July to December 2009 alone, 343,476 percent women visited antenatal clinic of which $253,459(73.7 \%)$ underwent HIV testing with the same (2.4\%) Positively rate as the previous year. Unfortunately out of those tested positive only $57.7 \%$ received ARV/NVP [15].

A comparison of the number of pregnant women receiving ARV/NVP during childbirth from January and December 2009(6.721) to the estimated 84.189 HIV-positive pregnant women in 2009/02 puts national PMTCT coverage 8\% PMTCTcoverege has thus showed incremental improvement over the past few years where it was 5\% in $2006 / 07$ and $6 \%$ in $2007 / 08[5,15]$.

Out of Africa- in Aisa, prevalence rates among pregnant women are mainly below 5\%, but because of the enormous population of the region ( $60 \%$ of the world's population) the percentages are of grave concern. Low national prevalence rate do not reflect localized epidemics in manly place, such as in china and India. HIV prevalence rate a mange pregnant women in Latin America is rising as there are at least 1.5millin people living with HIV/AIDS (PLWHAs) in Latin America and an additional 420.000PLWHAs in Caribbean. Which has, next to Africa, the second highest HIV/AIDS prevalence rate in the world. In twelve countries in this region prevalence among pregnant women is greater than $1 \%$ [16]

Strategy in prevention of mother to child transmission (PMTCT)of HIV/AIDS- there is a four recommended prong strategy to prevent HIV among infant and young children .This includes key intervention to be implemented as a component of overall maternal, newborn and child health services [17].

Prong 1: Primary prevention of HIV among women of reproductive age within services related to reproductive health such as antenatal care, postpartum care and other health and HIV service delivery points including working with community structures.

Prong 2: Providing appropriate counseling and support to women living with HIV to enable them mark an informed decision about their future reproductive life .with special attention to preventing unintended pregnancies.

Prong 3: For pregnant women living with HIV, ensure HIV testing and access to the antiretroviral drugs that will help mothers own health and prevent infection being passed on to their babies during pregnancy, delivery and breastfeeding.

Prong 4: Better integration of HIV care, treatment and support for women pound to be positive and their families.

\section{Role of ART drugs in PMTCT:-}

A number of antiretroviral drug regimens - based on zidovudine, zidovudine and lamivudine, or nevirapine, or combination used in highly active antiretroviral therapy -have been shown to be effective in reducing the mother to child transmission of HIV. The choice of antiretroviral drug regimen should be made locally. Taking into account issues of feasibility, efficacy and cost [18].

The WHO says that PMTCT programmers are "strongly enlarged "to implement the 2010 recommendations but acknowledges that this might not be possible for all countries. In this situation, there are previous regimens that have been used and might be implemented, these option are shown in the table below [19]. Under the 2006 recommendations, if a women receives at least four weeks of AZT during pregnancy, doctors may choose to omit her dose of nevirapine from the recommended regimen .in this case she will not have to take 3TC during labor or to take any drugs after birth .However .her baby must still receive nevirapine, and should , and also receive AZT four weeks instead of one, If the women receives less than four weeks of AZT during pregnancy then her baby should receive AZT for four weeks instead of one [20]. 


\section{Methods and Material:-}

Study Area and period:-

Addis Ababa is the capital city of Ethiopia. It is located in the central highlands of Ethiopia. Covering an area of 530 $\mathrm{km}^{2}$ and accommodate about $30 \%$ of the total urban population in Ethiopia (Fig. 1). It currently has a total population of 3.1 million. It has 33 hospitals and 28 health centers. Of the total hospitals.5 are managed under health bureau of the city administration [17].

Four hospital are manage by federal $\mathrm{MOH}$, one is university hospital (under Addis Ababa university) and the rest are either privately owned by nongovernmental (NGO) and other governmental organization .All health centers are arranged and managed under health bureau of 10sub-cities. Entoto No.1 and yaka health center are under health bureau of yaka sub-city. The study was conducted in yaka health center which is located around Sholla Gebeya Addis Ababa, Ethiopia. Yaka health center is a governmental health center established in 1970 and became operational since 1972. Now days, there are 111,440.00 are served in the health center of the total HIV patient 1439 are female and 597 current patient on ART at the health center.

\section{Study Design and Population;-}

A cross sectional survey of factors that affect prevention of Mother to child transmission (PMTCT) of HIV/AIDS among women attending in yaka health center. More than 111,440 served in the health center including both genders are source of population and sample was drawn from 597 women with HIV positive who are on ART service in Yaka health center.

\section{Sampling and Data Management:-}

Convenient sampling method was used to select Yaka health center as study area. Which is under Yaka sub-city .Random sampling method was used to select the real representative sample All ART service providers who are at work in the selected health center at the time of the study.

An exit interview was made on the selected HIV positive structured interview comprising 10 questions was used to obtain the information from provider for this study .The inter contained two section a section on respondents sociodemographic characteristics, and a section on factors affecting PMTCT. The questionnaire was pilot tested at one health center .which was not involved in the final survey and certain correction was made on the questionnaire based on the feedback obtained. Data was collected by the research team.

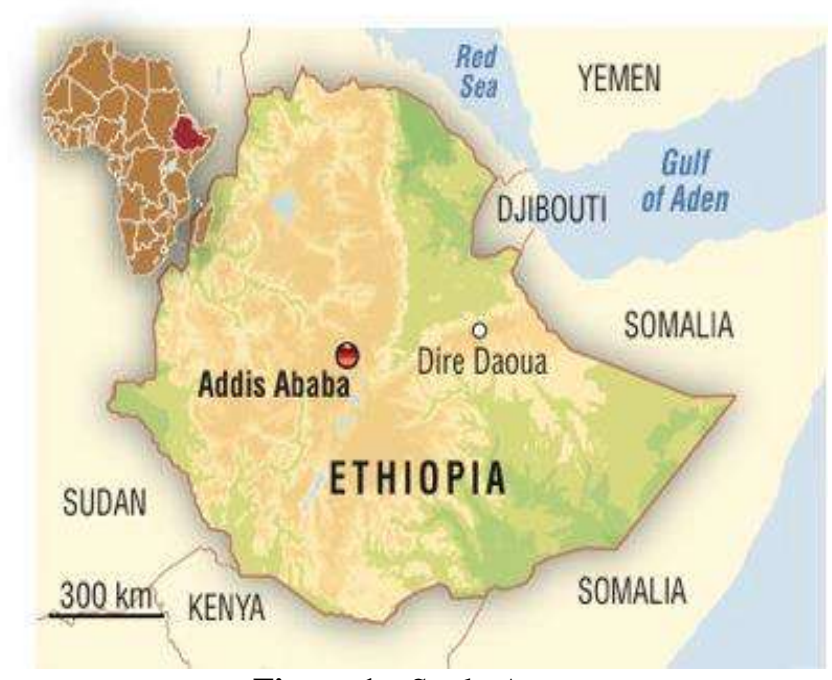

Figure 1:- Study Area

\section{Data Analysis:-}

Data was entered and analyzed using manually. Simple descriptive statistics was used for data analysis. The result were present as range, frequencies and in the form of frequency table. The Study variables were dependent $\&$ and 
variables. The dependent variables are factors affecting PMTCT among female with HIV positive and the independent demographic factors, level of education, year, of service, current job position.

\section{Result and Discussion:-}

\section{Result:-}

A total of 300 HIV positive women and 5 service providers were interviewed in the present study. Majority of HIV women lies in the age group of 26-35 year and 55\% of them have more than two children .from ethnics and religious pattern, Amhara ethnic and Christian religious were taken Lange part (53\% and 67\% respectively). Large number of the women have middle income (73\%) and $56 \%$ of the women are house wife as shown in the table (1).

Table 1:- Socio - demographic characteristics of women with HIV positive in Yaka Health center

\begin{tabular}{|c|c|c|}
\hline Variables & Number & Percentage (\%) \\
\hline \multicolumn{3}{|l|}{ Age in year } \\
\hline $15-19$ & 26 & 9 \\
\hline $20-24$ & 83 & 28 \\
\hline $25-29$ & 61 & 20 \\
\hline $30-34$ & 76 & 25 \\
\hline $35-39$ & 31 & 10 \\
\hline $40-44$ & 15 & 5 \\
\hline $45-49$ & 10 & 3 \\
\hline \multicolumn{3}{|l|}{ Have children } \\
\hline Yes & 165 & 55 \\
\hline \multicolumn{3}{|c|}{ No. of children } \\
\hline one & 135 & 45 \\
\hline Two & 108 & 36 \\
\hline$>$ three & 57 & 19 \\
\hline \multicolumn{3}{|c|}{ Religion } \\
\hline Orthodox & 201 & 67 \\
\hline Muslim & 69 & 23 \\
\hline Others & 30 & 10 \\
\hline \multicolumn{3}{|c|}{ Ethnicity } \\
\hline Amhara & 159 & 53 \\
\hline Oromo & 78 & 26 \\
\hline Tigray & 57 & 19 \\
\hline Sothern Nationalities & 6 & 2 \\
\hline \multicolumn{3}{|c|}{ Occupation } \\
\hline Housewife & 168 & 56 \\
\hline Civil service & 102 & 34 \\
\hline Private & 18 & 6 \\
\hline Business & 12 & 4 \\
\hline \multicolumn{3}{|l|}{ Economic status } \\
\hline Low income & 63 & 21 \\
\hline Middle income & 219 & 73 \\
\hline High income & 18 & 6 \\
\hline
\end{tabular}

Overall numbers of women living with their partners were 189(i.e 63\%)Almost all of their partners are HIV positive (61\%) and comparable number of them agreed that their partners help them more than expected (49\%) and not help them at all $(48 \%)$. The present study showed that few numbers of them are free from pregnancy or lactating $(27 \%)$ $.67 .66 \%$ and $5.33 \%$ were pregnant and lactating women respectively as mentioned as show. 
Table 2: PMTCT service of women with HIV positive in Yaka Health center .Addis Ababa August, 2011

\begin{tabular}{|c|c|c|}
\hline Variables & Number & Percentage $(\%)$ \\
\hline \multicolumn{3}{|l|}{ Pregnant or Lactation? } \\
\hline Pregnant & 203 & 68 \\
\hline Lactating & 16 & 5 \\
\hline No preg or Lactating & 81 & 27 \\
\hline \multicolumn{3}{|l|}{ Knowledge about HIV/AIDS? } \\
\hline Yes & 161 & 87 \\
\hline No & 39 & 13 \\
\hline \multicolumn{3}{|l|}{ Source of information on HIV/AIDS } \\
\hline Health worker & 39 & 13 \\
\hline From other HIV positive person & 9 & 3 \\
\hline $\begin{array}{c}\text { Friends } \\
\end{array}$ & 12 & 4 \\
\hline Mass Media & 171 & 57 \\
\hline Others/please specify & 69 & 23 \\
\hline \multicolumn{3}{|l|}{ Modes of transmission of HIV/AIDS } \\
\hline $\begin{array}{c}\text { Sexual intercourse } \\
\end{array}$ & - & 89 \\
\hline Contaminated sharps & - & 84 \\
\hline Mother tochild & - & 79 \\
\hline Breast feeding & - & 8 \\
\hline Kissing, sharp, cup/utensils sharp toilets & - & 7 \\
\hline Other/specify & - & 3 \\
\hline \multicolumn{3}{|l|}{ Have you heard about PMTCT } \\
\hline Yes & 222 & 74 \\
\hline No & 78 & 26 \\
\hline \multicolumn{3}{|l|}{ Methods for PMTCT } \\
\hline Avoidance of breastfeeding & 6 & 2 \\
\hline HIV counseling and test & 15 & 5 \\
\hline Quality obstetrical service & 12 & 4 \\
\hline Use of contraceptive & 24 & 8 \\
\hline Use of ART drugs/ & 240 & 80 \\
\hline Others/specify & 3 & 1 \\
\hline \multicolumn{3}{|l|}{ Proper advice or on PMTCT } \\
\hline Yes & 237 & 79 \\
\hline No & 63 & 21 \\
\hline \multicolumn{3}{|l|}{ Living alone or with partner } \\
\hline With partner & 189 & 63 \\
\hline Without partner & 111 & 37 \\
\hline \multicolumn{3}{|l|}{ To what extent he help you on PMTCT } \\
\hline More than expected & 147 & 49 \\
\hline Do not help me & 144 & 48 \\
\hline Not mentioned & 9 & 3 \\
\hline
\end{tabular}

Structured interview was done on PMTCT service providers to the document complete and to clearly identify the factors on PMTCT service .A total of 5 nurses were participated in the study, they have more than 3years experience and they took short term training on PMTCT.

They thought that they have providing adequate PMTCT service in the health center .The also mentioned that some of the obstacles on the PMTCT service are low level of awareness of the patient, lack of integration of PMTCT in family planning and work load .PMTCT coverage in Ethiopia showed incremental improvement over the past few years where it was $5 \%$ in $2006 / 07$ and $6 \%$ in 2007/08 [5,15]. They agreed than the coverage of PMTCT service has been increasing in the health center beside the presence of certain obstacles indicated in the above. They also recommended that PMTCT service should be integrated with family planning, service provides should get continues training to improve the level of service in the health center. 


\section{Discussion:-}

Mass media have been used all around the world as a total in the combat against HIV/AIDS .one of the desired effects of mass media interventions is an increase in Knowledge about HIV/AIDS. The educational role of mass as a whole is crucial, as HIV/AIDS communication is most often received from this channel rather than from interpersonal sources.

Moreover, here is evidence that mass media exposure may promote interpersonal communications about HIV/AIDS. A study conducted in India suggested that people with media exposure to HIV/AIDS information were significantly more likely to discuss HIV related topics within social networks. Mass media in china has been also a major source of HIV information to the public [23]. In our study mass media found to be was the main source of information for the women to have adequate Knowledge about HIV/AIDS indicated in table [2].

This highlights the crucial role of mass media education in influencing HIV Knowledge and attitudes .especially in our setting where HIV Knowledge. Unprotected sexual relationship. Contaminated blood or blood product , pregnant mother to child and other routes like saliva, tears and urine of infected individuals with high concentrations are the mode of transmission of HIV/AIDS [24].unprotected sexual intercourse(89\%), contaminated sharps $(84 \%)$ and mother to child $(79 \%)$ were the main mode of transmission of HIV/AIDS identified by the women. These three mode of transmissions are comparable indicated in (table.2).

This indicates that the respondents have better knowledge and understanding on the mode of transmission of HIV/AIDS. More than half of the women (74\%) responded that the heard PMTCT. Many researchers suggested that the use of antiretroviral drug help mothers own health and prevent infection being passed on to their babies during pregnancy, delivery and breastfeeding [17]. Use of ART (80\%) as a method of PMTCT that was selected by large number of the women. The percentage of who responded "yes for the question; have you received proper advice on PMTCT? Were 79\% indicated in (table.2) the previous books mentioned certain issues on the level of PMTCT services. According to these books. More 616.763 pregnant women made at least one antenatal clinic visits during the last fiscal year, and 417.841 underwent HIV testing, of which 10.267 (2.4) of the pregnant women tested positive in 2009. Of the total pregnant women diagnosed with HIV. Only 6.466 (63\%) received antiretroviral prophylaxis (ARV/NVP) and only 5,267 infant PMTCT prophylaxis in the same year. The proportion of diagnosed HIV positive pregnant mother receiving antiretroviral prophylaxis was significantly greater that the $52 \%$ in $2007 / 08$ $[7,14]$.

A recent study also showed that a PMTCT strategy focused on increasing contraception among HIV -positive women could avert $29 \%$ more HIV -positive birth than prophylactic nevirapine alone at the same level of expenditure [22]. This highlights contraceptives have a crucial role in PMTCT .In contrast. The present study showed that less number of the women know that contraceptive can be considered as a strategy for PMTCT.

\section{Conclusion and Recommendation:-}

Knowledge of the patient on the strategies of PMTCT and its importance on non -HIV positive birth and lack of integrating family planning to PMTCT are the main factors. Integrating HIV treatment and care service with HIV prevent interventions is vital to avert HIV - positive births. Improving patient awareness on PMTCT has to get great attention and different strategies should be devised to cope-up-the problem.

\section{Reference:-}

1. UNAIDS, Report on the global AIDS epidemic. 2008

2. World health organization, toward universal access: scaling up priority HIV/AIDS interventions in the health sector: progress report 2008.

3. UNAIDS, prevent mother to child transmission of HIV: The challenge. 2010.

4. UNAIDS Report on the Global HIV/AIDS Epidemic : Geneva ,Joint Unit Nations programmer on HIV/AIDS, 2000

5. World Health Organization. An assessment of interaction between global health initiative and country health system .Lancet 2009, 373:2137-2169.

6. Nigatu T,woldegebriel $\mathrm{Y}$.Analysis of the prevention of mother to child Transmission (PMTCT) service utilization in Ethiopia:2006-2010.Report health.2011,16;8:6 
7. Federal Democratic Republic of Ethiopia and Federal HIV/AIDS prevention and control office. Report on progress towards implementation of the UN Declaration of Commitment on HIV/AIDS.2010

8. UNAIDS, Report on the global AIDS epidemic, Geneva, 2010.

9. Mekonon Y, private sector partnerships -Ethiopia (2009). Mobile HIV counseling and testing: A new lens through which to view the urban HIV epidemic in Ethiopia.

10. UNICEF, UNAIDS, WHO, UNFPA, and UNESCO, children and AIDS: fifth stocktaking Report, New York, 2010.

11. UNICEF, Mother to child Transmission of HIV/AIDS: Reducing the Risk the MNH program is working to reduce the spread of HIV by promotion clinical practice that encourage prevention before, during and after pregnancy and childbirth.2009.

12. Prevention Mother to child transmission of HIV (PMTCT). Available at C: Documents and Setting /user/Desktop/Pmctc / preventing Mother- to-child Transmission (PMTCT) of HIV.htm.

13. Muko KN, Tchangwe GK,Ngwa VC ,Njoya L. Preventing mother - to child transmission factor affecting mothers choice Journal of social Aspects of HIV/AIDS,2004,1.

14. WHO, UNAIDS and UNICEF. Towards Universal Access. Scaling uppriority HIV/AIDS intervention in the health sector, Progress Report 2010.

15. US Census Bureau. HIV/AIDS country profiles, Available at htt:/www.census.gov/ipc/www/hivctry.httl.Novber18,2002)

16. Federal HAPCO. The Ethiopia strategic plan for intensifying Multi-sectoral HIV Response (SPM II). Addis Ababa, Ethiopia, 2009.

17. Federal Ministry of Health (FMOH). Accelerating to HIV/AIDS Treatment in Ethiopia .ROAD MAP for 20072010.

18. UNAIDS, Report on the global HIV/AIDS epidemic; July 2002.

19. UNAIDS. Preventing Mothe-to- child Transmission (PMTCT) of HIV .Fectsheet on the status of national PMTCT responses in the most affected countries, 2010.

20. WHO, Strategic approaches to the prevention of HIV infection in infants.2002.

21. WHO, Strategic approaches to the prevention of HIV infection in infants Report of a WHO meeting, Morges Switzerland, 2002.

22. Reynolds HIV, Janowitz B, Homan R,Johnson L (2006) The value of contraception to prevent perinatal HIV transmission .sex transm Dis 33:350-356.

23. Li Li, Zunyou Wu, Chunqing Lin Jihui Guan, Mary Jane Rotheram-Borus, Yao Lu (2010).Mass Media and HIV/AIDS in china. J Health Commun; 14(5):424-438.

24. CDC: Transmission of HIV positive Associated with Exposure of Mocous Membrane contaminated Blood MWR July 11,1997/ Vil.46/N0.27 